\title{
KESIAPAN PROGRAM DAN STRATEGI PENGEMBANGAN PERIKANAN TANGKAP LAUT PADA KAWASAN MINAPOLITAN
}

\author{
Armen Zulham dan Subhechanis Saptanto \\ Balai Besar Penelitian Sosial Ekonomi Kelautan dan Perikanan \\ JI. KS. Tubun Petamburan VI Jakarta 10260 \\ Telp. (021) 53650162, Fax. (021)53650159
}

Diterima 7 Mei 2012 - Disetujui 20 Juni 2012

\begin{abstract}
ABSTRAK
Program minapolitan merupakan salah satu program pembangunan yang bertujuan untuk mendorong pertumbuhan pada kawasan berbasis kelautan dan perikanan. Pada perikanan tangkap laut, pelabuhan perikanan dijadikan zona inti dari program minapolitan dengan tujuan untuk merevitalisasi dan mengoptimalkan pemanfaatan seluruh infrastruktur yang terdapat pada kawasan tersebut. Pemanfaatan infrastruktur itu diharapkan dapat menstimulasi tumbuhnya berbagai kegiatan ekonomi disekitar kawasan pelabuhan perikanan. Tulisan ini didasarkan pada hasil mail survey dari 67 pelabuhan perikanan dan studi mendalam pada 9 (sembilan) pelabuhan perikanan. Tujuan dari tulisan ini adalah untuk menilai kesiapan pelabuhan perikanan dalam melaksanakan program minapolitan dari aspek sosial ekonomi dan menganalisis strategi pelaksanaan program pembangunan pada kawasan minapolitan. Tujuan pertama diperoleh dengan teknik pembobotan berdasarkan 6 (enam) pilar minapolitan, tujuan kedua diperoleh dengan analisis SWOT. Hasil analisis data menunjukkan: 5 (lima) pelabuhan perikanan masuk dalam kategori mandiri, 20 pelabuhan perikanan masuk dalam kategori maju, 22 pelabuhan perikanan masuk dalam kategori pemula dan 8 (delapan) pelabuhan perikanan masuk dalam kategori perintis. Pelaksanaan program minapolitan harus dikonsentrasikan pada pelabuhan perikanan mandiri dan pelabuhan perikanan maju. Strategi pengembangan minapolitan pada pelabuhan perikanan katagori mandiri adalah strategi ST (Strengths-Threats). Strategi ini dilakukan dengan memobilisasi infrastruktur yang ada, diikuti dengan berbagai inovasi kebijakan untuk mengendalikan ancaman agar tujuan program minapolitan dapat terwujud. Pada pelabuhan perikanan maju didorong dengan strategi SO (Strengths-Opportunities). Strategi SO dilakukan melalui peningkatan kerjasama dengan Pemda untuk memperbaiki kualitas infrastruktur pelabuhan perikanan. Pengembangan program minapolitan kedepan harus dilakukan dengan konsep klasterisasi pelabuhan perikanan, untuk menghindari persaingan tidak sehat antara pelabuhan perikanan.
\end{abstract}

\section{Kata Kunci: minapolitan, perikanan laut, SWOT, klusterisasi}

\section{Abstract: The Development Strategy of Marine Fisheries in "Minapolitan" Areas. By: Armen Zulham and Subhechanis Saptanto.}

Minapolitan known as one of the marine and fisheries development program in order to stimulate the economic growth in the fisheries areas. In the marine fisheries, the fishing port were chozen as the main location to the implementation of minapolitan program. The aims are to revitalisation and to optimize the infrastructure in fisheries fishing ports. This research was used the data from 67 fishing port in all part of Indonesia. Indept studies were conducted in 9 (nine) fishing ports. The main findings of the research revealed the readiness of fishing port to implementing the minapolitan program classified into for categories; 5 (five) fishing port classified as self developed, 20 fishing port classified as developped, 
22 fishing ports remain developing and 8 (eight) fishing ports classified as under developing. Based on SWOT analysis, recommendation for the implementation of minapolitan program should be focused on the fishing ports which were classified as self developed and developed. The development strategy to carry out the minapolitan program in the fishing port under self developed categories was ST (Strengths-Threats) strategy. Main while, the strategies to implement minapolitan program in the fishing ports under developed category was SO (Strengths-Opportunities) strategy. This research also recommended that implementation of minapolitan program among fishing ports should be conduct under cluster policy to avoid the unfair competition among fishing ports.

Keywords: minapolitan, marine fisheries, SWOT, cluster

\section{PENDAHULUAN}

Kementerian Kelautan dan Perikanan mengembangkan program minapolitan sebagai strategi untuk mendorong pertumbuhan pada sektor kelautan dan perikanan. Minapolitan didefinisikan sebagai konsep pembangunan wilayah dengan pendekatan sistem manajemen kawasan berdasarkan prinsip: integrasi, efisiensi, kualitas, dan akselerasi (KKP, 2010). Sebagai kawasan pertumbuhan ekonomi, maka kegiatan ekonomi pada kawasan minapolitan harus: 1). dikembangkan berdasarkan potensi kawasan; 2). menghilangkan ketidaksempurnaan pasar; 3). mendorong perubahan struktural; 4). menentukan pola investasi yang tepat; 5). memahami perubahan sosio-budaya; 6). penguatan sistem administrasi yang kuat (Jhingan, 1999).

Keberhasilan program minapolitan pada satu kawasan dapat diukur dengan tiga indikator, yaitu: meningkatnya produksi perikanan, tersedianya lapangan kerja dan meningkatnya pendapatan masyarakat. Pada perikanan tangkap laut, konsep ini diimplentasikan pada pelabuhan perikanan, dimana pelabuhan tersebut dijadikan zona inti kawasan minapolitan. Hal ini didasarkan pada 2 pertimbangan yaitu: pertama, tingginya aktivitas perikanan dalam kawasan pelabuhan dan kedua dapat mendorong tumbuhnya aktivitas lain diluar pelabuhan perikanan.

Direktorat Jenderal Perikanan pada tahun 1994 membagi pelabuhan perikanan menurut
4 tipe, yaitu: Pelabuhan Perikanan Samudera (PPS), Pelabuhan Perikanan Nusantara (PPN), Pelabuhan Perikanan Pantai (PPP), Pangkalan Pendaratan Ikan (PPI). Klasifikasi tersebut didasarkan pada aspek teknis dari sebuah pelabuhan perikanan dan tidak mempertimbangkan aspek sosial-ekonomi dari pelabuhan perikanan. Berdasarkan Klasifikasi teknis tersebut, maka di Indonesia saat ini terdapat: 6 PPS, 14 PPN, 43 PPP, dan 919 PPI serta 3 pelabuhan perikanan swasta.

Permasalahan pelaksanaan minapolitan adalah ketika pelabuhan perikanan tersebut belum siap melaksanakan program minapolitan (karena peran aspek sosial ekonomi tentang: infrastruktur, masyarakat dan bisnis, sumber daya dan tata ruang, kelembagaan, teknologi serta kebijakan dan governance belum menjadi pertimbangan). Padahal, pelabuhan perikanan tersebut ditunjuk sebagai lokasi minapolitan berdasarkan Surat Keputusan Menteri Kelautan dan Perikanan No. 12/Men/2010.

Pada perikanan tangkap laut, masalah yang dihadapi dalam implementasi program minapolitan adalah : pertama, pada tingkat nasional, akurasi penunjukkan pelabuhan perikanan sebagai kawasan minapolitan banyak dipertanyakan. Kedua, pada tingkat pelabuhan perikanan terdapat keragaman kondisi sosial ekonomi dari pelabuhan perikanan tersebut. Kedua hal tersebut sangat berpengaruh pada keberhasilan program minapolitan pada pelabuhan perikanan. Selain itu ketersediaan stok ikan diperairan harus menjadi pertimbangan pada setiap 
pelabuhan perikanan yang melaksanakan program minapolitan.

Tujuan penelitian ini adalah: 1) melakukan identifikasi kesiapan pelabuhan perikanan menurut kategori kesiapan pelaksanaan program minapolitan; dan 2) mengusulkan strategi pengembangan kawasan minapolitan.

\section{METODOLOGI}

Pengumpulan data dilakukan melalui dua cara, yaitu: mail survey dan survey. Mail survey diperoleh dari 67 pelabuhan perikanan yang mencakup PPS, PPN, PPP, PPI. Survey dilakukan pada 9 lokasi minapolitan, yaitu: Pelabuhan Perikanan Samudera (PPS) Belawan, Pelabuhan Perikanan Nusantara (PPN) Sungai Liat, PPN Pelabuhan Ratu, PPS Cilacap, Pelabuhan Perikanan Pantai (PPP) Muncar, PPS Bitung, PPN Ternate, PPN Ambon, PPP Tamperan.

Hasil survey dan mail survey diperoleh kesiapan pelabuhan perikanan dalam pelaksanaan program minapolitan, serta strategi mengembangkan kawasan minapolitan. Data mail survey dan survey diolah dengan teknik pembobotan sehingga diperoleh klasifikasi pelabuhan perikanan. Hasil klasifikasi tersebut selanjutnya digunakan untuk menganalisa strategi pengembangan perikanan tangkap laut pada kawasan minapolitan pada pelabuhan perikanan dengan teknik Strenght - Weakness - Opportunities - Threat yang dikenal sebagai SWOT(Saaty, 1993; Sianipar dan Entang, 2008). Analisis SWOT dalam tulisan ini hanya dilakukan untuk pelabuhan perikanan yang masuk dalam katagori mandiri dan maju. Prinsip analisis SWOT adalah mengevaluasi kekuatan dan kelemahan, serta memanfaatkan peluang dan mengendalikan ancaman dalam pengembangan perikanan tangkap pada kawasan pelabuhan perikanan pelaksana program minapolitan.

Dengan acuan aspek sosial ekonomi pada 6 pilar minapolitan (Zulham et al., 2010a; dan Zulham et.al, 2010b) sebagai dasar menilai kemampuan melaksanakan program pembangunan, diperoleh keragaman aspek sosial ekonomi dari berbagai pelabuhan perikanan yang diamati. Oleh sebab itu, untuk mempersempit keragaman tersebut dikembangkan kriteria kemampuan pelabuhan perikanan dalam pelaksanaan program minapolitan. Klasifikasi tersebut didasarkan pada pemberian bobot dari pilar minapolitan: infrastruktur (20), masyarakat dan bisnis (20), sumber daya dan tata ruang (15), kelembagaan (15), teknologi (15), kebijakan dan tata kelola pemerintahan (15). Penentuan bobot tersebut ditentukan oleh tim peneliti berdasarkan peringkat kepentingan dari aspek sosial ekonomi terkait. Klasifikasi kemampuan pelaksanaan program minapolitan tersebut terbagai atas 4 kategori, yaitu: kategori pelabuhan perikanan Mandiri (nilai bobot > 75-100). kriteria utama adalah : a) aspek sosial ekonomi terkendali dan terintegrasi dengan baik; b) Unit Pengolahan Ikan (UPI) berkembang pesat; dan c) Hasil tangkapan sebagian besar diserap oleh UPI jika kekurangan pasokan maka kebutuhan ikan didatangkan dari luar daerah (termasuk impor) dan sebagian ikan tersebut dipasarkan untuk kebutuhan konsumsi. Pelabuhan perikanan Maju (nilai bobot $>50-75$ ), ciri-cirinya mencakup : a) aspek sosial ekonomi sudah terkendali namun belum terintegrasi; b) UPI mulai berkembang; c) Hasil tangkapan nelayan sekitar $50 \%$ diserap oleh UPI, sisanya dijual keluar daerah untuk berbagai keperluan. Pelabuhan perikanan Pemula (nilai bobot >25-50) ciri-cirinya adalah : a) aspek sosial belum tekendali dan terintegrasi; b) UPI sudah ada namun masih dalam skala rumah tangga dan sulit memasarkan; dan c) Hasil tangkapan nelayan sebagian besar untuk konsumsi dan hanya sedikit yang diserap oleh UPI. Pelabuhan perikanan Perintis (nilai bobot 0-25) ciricirinya adalah : a) aspek sosial ekonomi belum diperhatikan; b) UPI belum ada; dan c) Hasil tangkapan nelayan dipasarkan hanya untuk konsumsi rumah tangga. 


\section{KESIAPAN PELAKSANAAN PROGRAM MINAPOLITAN}

Hasil pembobotan dengan mempertimbangkan aspek sosial ekonomi tersebut, menunjukkan terdapat 5 pelabuhan perikanan yang masuk dalam katagori mandiri, 20 pelabuhan perikanan masuk dalam katagori maju, 33 pelabuhan perikanan masuk dalam katagori pemula dan 8 pelabuhan perikanan masuk dalam katagori perintis. Sebaran pelabuhan perikanan menurut katagori tersebut dapat diperhatikan pada Tabel 1 .

Penetapan pelabuhan perikanan yang sesuai sebagai lokasi pelaksanaan program minapolitan. harus mempertimbangkan tiga indikator (telah diuraikan pada bagian metodologi). Refleksi dari ketiga indikator tersebut tercermin melalui proses pembobotan tentang kemampuan pelabuhan perikanan dalam melaksanakan program minapolitan. Pada kategori mandiri dan maju, kemampuan pelabuhan perikanan untuk meningkatkan produksi dan menyediakan lapangan kerja cukup besar, karena infrastruktur yang tersedia cukup memadai. Infrastruktur ini didukung oleh kemampuan bisnis pada masyarakat disekitarnya, berfungsinya kelembagaan di dalam masyarakat, serta tersedianya teknologi. Selain itu pada kategori mandiri potensi untuk peningkatan pendapatan cukup besar, karena pasar untuk hasil tangkapan cukup

\section{Tabel 1. Katagori Kemampuan Pelaksanaan Program Minapolitan menurut Pelabuhan Perikanan Tahun 2011.}

Table 1. The Readiness Catagories of Minapolitan Program Based on Fishing Ports, 2011.

\begin{tabular}{|c|c|c|}
\hline $\begin{array}{l}\text { No/ } \\
\text { No }\end{array}$ & $\begin{array}{l}\text { Kategori (Kisaran Bobot)/ } \\
\text { Catagories (Value Interval) }\end{array}$ & $\begin{array}{l}\text { Pelabuhan Perikanan/ } \\
\text { Fishing Ports }\end{array}$ \\
\hline 1 & $\begin{array}{l}\text { Mandiri/ Self developed } \\
(>75-100)\end{array}$ & $\begin{array}{l}\text { PPS Bitung }(80,5) \text {; PPN Palabuhan Ratu }(78,55) \text {; } \\
\text { PPS Kendari }(78,3) \text {; PPS Nizam Zachman }(77,65) \text {; } \\
\text { dan PPP Muncar }(76,6)\end{array}$ \\
\hline 2 & Maju/ Developed (>50-75) & $\begin{array}{l}\text { PPN Pemangkat (74,65); PPN Pekalongan }(74,6) ; \text { PPN } \\
\text { Sibolga }(74,6) ; \text { PPN Ternate (74); PPN Kejawanan }(73,9) ; \\
\text { PPN Brondong (73,55); PPP Sungai Rengas }(71,85) ; \\
\text { PPS Belawan (70,8); PPN Tanjung Pandan }(70,4) ; \text { PPS } \\
\text { Sungailiat (70); PPI Paotere }(69,9) ; \text { PPS Cilacap }(68,8) ; \\
\text { PPP Idi }(68) ; \text { PPP Tegal Sari }(67,7) ; \text { PPN Prigi }(64,5) ; \text { PPS } \\
\text { Bungus }(64,2) ; \text { PPN Ambon }(64) ; \text { PPP Sorong }(60,95) ; \text { PPP } \\
\text { Bajomulyo }(60,7) ; \text { dan PPP Tamperan }(59,85) .\end{array}$ \\
\hline 3 & $\begin{array}{l}\text { Pemula/Remain developing } \\
(>25-50)\end{array}$ & $\begin{array}{l}\text { PPI Bengkulu (50); PPP Kupang (49,95); PPI Pamayangsari } \\
(49,95) ; \text { PPN Karangantu (49,95); PPN Pengambengan } \\
\text { (49,9); PPI Ujung Serangga (49,9); PPP Tumumpa }(49,8) ; \\
\text { PPP Kwandang (49,78); PPI Bengkalis (49,78); PPP Sadeng } \\
\text { (49,75); PPP Labuhan Lombok }(49,75) ; \text { PPI Pagimana } \\
(49,7) ; \text { PPI Karangsong }(49,7) ; \text { PPP Wayangan }(49,58) ; \text { PPP } \\
\text { Carocok Tarusan }(49,55) ; \text { PPI Banggae }(49,55) ; \text { PPN Teluk } \\
\text { Awang }(49,5) ; \text { PPI Lonrae }(49,5) ; \text { PPI Batu Licin }(49,4) ; \text { PPP } \\
\text { Tasik Agung (49,3); PPN Tual }(49,3) \text {; PPI Lantora }(49,3) ; \\
\text { PPP Pantai Tawang }(49,1) ; \text { PPI Amurang }(49,1) ; \text { dan PPP } \\
\text { Kuala }(49,05) \text {. }\end{array}$ \\
\hline 4 & Perintis/Under developing (0-25) & $\begin{array}{l}\text { PPI Sadai (24,9); PPI Tanjung Adikarto (24,8); PPI Bulu- } \\
\text { Tuban (24,7); PPI Tilamuta (24,4); PPI Sape (24,4); PPI } \\
\text { Kasiwa (24,3); PPI Manggar Baru (23,55); dan PPI Teluk } \\
\text { Santong }(23,2) \text {. }\end{array}$ \\
\hline
\end{tabular}

*) Catatan : angka yang di dalam kurung menunjukkan bobot nilai pelabuhan perikanan

Sumber: Diolah dari hasil survey dan mail survey (2011)/Sources: Based on data from survey and mail survey (2011) 
bervariasi, namun pada kategori maju pasar untuk hasil tangkapan relatif terbatas.

Pada kategori pemula dan perintis peluang untuk meningkatkan produksi relatif terbatas, karena keterbatasan kemampuan dari armada penangkapan ikan. Infrastruktur yang kurang memadai, ikan hasil tangkapan sulit dipasarkan. Kendala tersebut akan mempengaruhi kemampuan untuk menyediakan lapangan kerja dan pendapatan. Berdasarkan tiga indikator tersebut, maka lokasi pelaksanaan program minapolitan perikanan tangkap laut lebih diutamakan pada pelabuhan perikanan yang masuk dalam kategori mandiri dan maju.

Implementasi program minapolitan pada pelabuhan perikanan katagori mandiri dan maju memerlukan strategi yang akurat, untuk menghindari persaingan antara pelabuhan-pelabuhan perikanan dalam melaksanakan aktivitasnya. Persaingan itu terjadi karena menangkap ikan pada fishing ground yang sama. Oleh sebab itu untuk mengatasi hal itu perlu dilakukan pendekatan klasterisasi pelabuhan perikanan. Klasterisasi ini dapat mendukung efisiensi investasi pengelolaan pelabuhan perikanan dan mendorong pemulihan stok ikan.

\section{PENGEMBANGAN KAWASAN MINAPOLITAN}

Strategi pengembangan kawasan minapolitan tangkap laut dirumuskan melalui analisis SWOT (Saaty, 1993; Sianipar dan Entang, 2008). Analisis ini menggali faktor internal: kekuatan (S) dan kelemahan (W) serta faktor eksternal: peluang (O) dan ancaman (T).

Faktor kunci keberhasilan dari pelabuhan perikanan yang masuk dalam kategori mandiri adalah seperti pada Tabel 2. Penetapan faktor kunci keberhasilan didasarkan pada total nilai bobot (TNB) terbesar, jika nilai TNB sama maka dipilih berdasarkan nilai bobot faktor (BF) terbesar, jika nilai BF sama pilih nilai bobot dukungan (NBD) terbesar, jika nilai NBD sama pilih nilai bobot keterkaitan (NBK) terbesar dan jika NBK sama maka pilih berdasarkan pengalaman.

Faktor kunci keberhasilan dari masing-masing faktor internal adalah: pelabuhan perikanan memiliki infrastruktur

Tabel 2. Faktor Kunci Keberhasilan Program Minapolitan pada Pelabuhan Perikanan yang Masuk dalam Katagori Mandiri Tahun 2011.

Table 2. The Successful Key Factors of Minapolitan Program on Self Developed Fishing Ports, 2011.

\begin{tabular}{|c|c|c|c|}
\hline \multirow{2}{*}{ No } & \multicolumn{3}{|c|}{ Faktor Internal/Factor Internal } \\
\hline & Kekuatan (S)/Strengths & No. & Kelemahan (W)/Weaknesses \\
\hline S1 & $\begin{array}{l}\text { Pelabuhan perikanan memiliki } \\
\text { infrastruktur yang memadai/Well } \\
\text { supported of fishing port infrastructure }\end{array}$ & W1 & $\begin{array}{l}\text { Pasokan ikan dan sistem distribusi ikan yang } \\
\text { tidak baik/Poor condition of fish supply and } \\
\text { distribution system }\end{array}$ \\
\hline S2 & $\begin{array}{l}\text { Memiliki rencana tata ruang dan bisnis } \\
\text { plan yang terencana/Have plan in land } \\
\text { use and business }\end{array}$ & W2 & $\begin{array}{l}\text { Manajemen/pengelolaan pelabuhan } \\
\text { perikanan yang tidak seragam/Different } \\
\text { management system in type of fishing port }\end{array}$ \\
\hline \multirow{2}{*}{ No } & \multicolumn{3}{|c|}{ Faktor Eksternal/ Factor Eksternal } \\
\hline & Peluang (0)/Opportunities & No. & Ancaman $(\mathrm{T}) /$ Threats \\
\hline 01 & $\begin{array}{l}\text { Permintaan ikan yang tinggi pada pasar } \\
\text { ekspor/High demand of fish export in } \\
\text { international market }\end{array}$ & $\mathrm{T} 1$ & $\begin{array}{l}\text { Banyaknya kegiatan IUU Fishing di daerah } \\
\text { penangkapan/Many IUU fishing activities in } \\
\text { some catch areas }\end{array}$ \\
\hline $\mathrm{O} 2$ & $\begin{array}{l}\text { Tingginya harga ikan di pasar ekspor/ } \\
\text { High price of fish in international market }\end{array}$ & $\mathrm{T} 2$ & $\begin{array}{l}\text { Adanya kebijakan Non Tarif pada pasar } \\
\text { ekspor/Non tariff barrier in international } \\
\text { market }\end{array}$ \\
\hline
\end{tabular}


yang memadai, serta pasokan ikan dan sistem distribusi ikan yang tidak baik. Faktor eksternal adalah permintaan ikan yang tinggi pada pasar ekspor dan banyaknya aktivitas IUU Fishing di daerah penangkapan ikan.

Hasil evaluasi, diperoleh total nilai bobot kekuatan $(S)=3,08$ dan total nilai bobot kelemahan $(W)=2,66$, sehingga diperoleh nilai ordinat pada kekuatan (S) sebesar 0,40 . Total nilai bobot peluang $(0)=2,16$ dan total nilai bobot ancaman $(T)=3,45$, sehingga diperoleh nilai ordinat pada ancaman ( $T$ ) sebesar $=-1,29$. Posisi pelabuhan perikanan yangmasuk dalam katagori mandiri berada pada kuadran ke II (Zulham et al., 2011). Analisis SWOT pelabuhan perikanan katagori mandiri dapat diperhatikan pada Lampiran 2. Strategi pelabuhan perikanan yang masuk dalam katagori mandiri adalah strategi Strengths- Threats (ST). Strategi ST adalah strategi yang memobilisasi infrastruktur yang ada dengan berbagai inovasi kebijakan untuk mengendalikan ancaman agar tujuan program minapolitan dapat terwujud.
Peluang dari pelabuhan yang masuk dalam kategori maju merupakan kesempatan dari pelabuhan perikanan tersebut untuk berkembang. Peluang tersebut didorong oleh dukungan pemda, permintaan ikan yang tinggi di pasar ekspor dan tingginya harga ikan di pasar ekspor. Sebaliknya ancaman yang dihadapi pelabuhan perikanan yang masuk katagori maju adalah tingginya kegiatan IUU Fishing diperairan Indonesia, konsumsi ikan domestik yang rendah dan adanya kebijakan non tarif di pasar ekspor yang mengancam pemasaran ikan hasil tangkapan nelayan.

Faktor kunci keberhasilan dari pelabuhan perikanan yang masuk dalam katagori maju adalah seperti pada Tabel 3. Penetapan faktor kunci keberhasilan didasarkan pada total nilai bobot (TNB) terbesar, jika nilai TNB sama maka dipilih berdasarkan nilai bobot faktor (BF) terbesar, jika nilai BF sama pilih nilai bobot dukungan (NBD) terbesar, jika nilai NBD sama pilih nilai bobot keterkaitan (NBK) terbesar dan jika NBK sama maka pilih berdasarkan pengalaman.

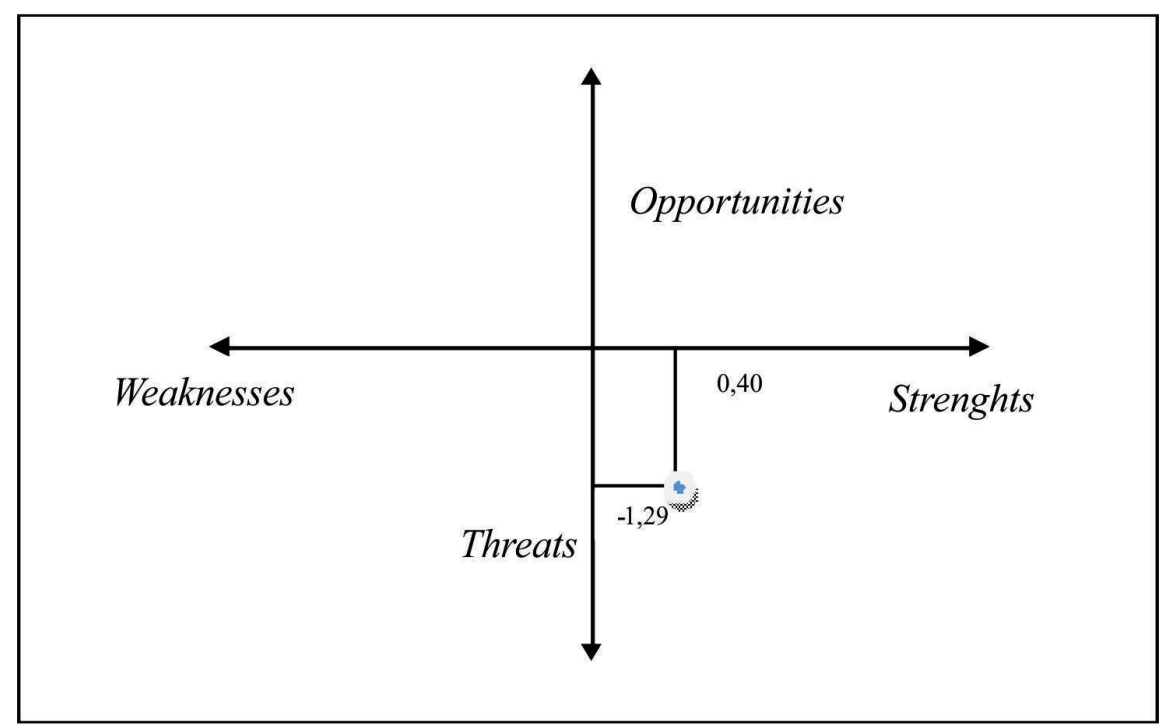

Gambar 1. Matriks Strategi Pelabuhan Perikanan yang Masuk Katagori Mandiri Program Minapolitan.

Figure 1. Matrix of Strategy on Self Development Fishing Ports MInapolitan. 
Faktor kunci keberhasilan dari masingmasing faktor internal adalah: pelabuhan perikanan memiliki infrastruktur yang memadai, serta pasokan ikan dan sistem distribusi ikan yang tidak baik. Faktor eksternal adalah terdapat dukungan dari Pemda untuk mengembangkan pelabuhan perikanan dan banyaknya aktivitas IUU Fishing di daerah penangkapan ikan.

Hasil evaluasi pada pelabuhan perikanan yang masuk katagori maju (Zulham et al., 2011) diperoleh total nilai bobot kekuatan $(S)=3,63$ dan nilai bobot kelemahan (W) $=2,56$, sehingga diperoleh nilai ordinat pada kekuatan (S) sebesar 1,07 . Sedangkan total nilai bobot peluang $(0)=3,64$ dan ancaman $(T)=2,51$ dan diperoleh nilai ordinat pada peluang $(0)$ sebesar 0,95 . Dengan demikian posisi pelabuhan perikanan yang masuk dalam kategori maju berada pada kuadran ke I. Analisis SWOT pelabuhan perikanan kategori maju dapat diperhatikan pada lampiran 3. Hasil perhitungan tersebut strategi yang dilakukan oleh pelabuhan perikanan dalam kategori maju adalah strategi Strengths-Opportunities (SO). Strategi SO tersebut berarti "tingkatkan kerjasama dengan Pemda untuk meningkatkan kualitas infrastruktur pelabuhan perikanan".

\section{REKOMENDASI KEBIJAKAN}

\section{Pelabuhan perikanan mandiri}

Strategi pengembangan pelabuhan perikanan mandiri dalam melaksanakan program minapolitan adalah:

1) Mengatur pemanfaatan dermaga pendaratan ikan yang efektif dan efisien agar proses bongkar ikan dapat berjalan dengan baik.

2) Memfasilitasi penyediaan BBM serta urusan administrasi yang cepat, sehingga pelabuhan perikanan menjadi tempat berlabuh yang menarik bagi armada penangkapan ikan.

3) Menerapkan prinsip traceability hasil tangkapan armada penangkapan ikan, bahan baku industri pengolahan ikan dengan menyempurnakan sistem pencatatan komoditas perikanan di kawasan pelabuhan perikanan.

4) Memperbaiki dan mempercepat sistem distribusi ikan ke pasar tujuan (termasuk ekspor) dengan prinsip aman, efektif dan efisien.

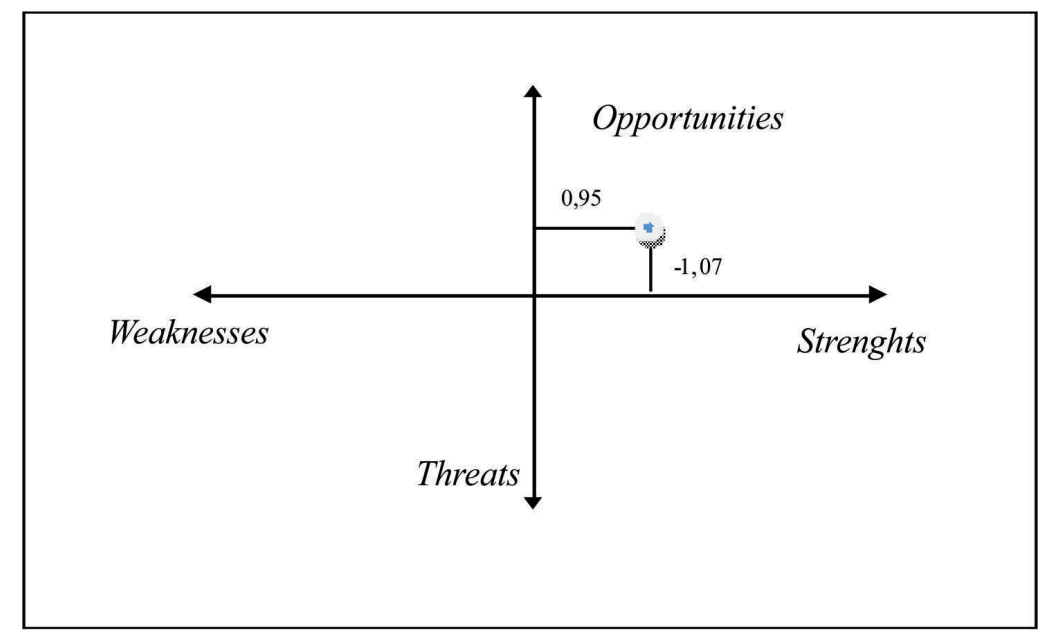

Gambar 2. Matriks Strategi Pelabuhan Perikanan Yang Masuk Katagori Maju Program Minapolitan.

Figure 2. Matrix of Strategy on Self Developed Fishing Ports Minapolitan. 
5) Meningkatkan pemantauan dan patroli di lapangan dalam rangka mengatasi masalah IUU fishing di perairan dengan cara melengkapi dan menyediakan sarana pemantau kegiatan IUU Fishing.

6) Mengakomodasi pelaksanaan hukum dan aturan perundang-undangan yang terkait dengan upaya pemberantasan kegiatan IUU Fishing di perairan dengan membentuk satuan pengawas dan penyidik pada kawasan pelabuhan perikanan.

\section{Pelabuhan perikanan maju}

Tindakan strategis yang perlu dilakukan pada pelabuhan perikanan maju dalam melaksanakan program minapolitan adalah:

1) Menyusun master plan kebutuhan infrastruktur pelabuhan perikanan yang dapat dibiayai oleh pemerintah daerah;

2) Menyusun master plan penguatan sumberdaya manusia dan kelembagaan masyarakat yang dapat dibiayai oleh pemerintah daerah;

3) Menyusun bussines plan kawasan pelabuhan perikanan yang dapat dibiayai pemda dan yang dapat dibiayai investor;

4) Menyusun bussines plan pembangunan jaringan distribusi ikan dari kawasan pelabuhan ke pusat pasar.

\section{Klasterisasi Pelabuhan Perikanan}

Klasterisasi beberapa pelabuhan perikanan terkait dengan program minapolitan harus dipertimbangkan karena stok ikan merupakan faktor pembatas dari perikanan tangkap laut. Armada pada berbagai pelabuhan perikanan yang berdekatan dan menangkap ikan pada WPP yang sama. Klasterisasi ini akan mengefisienkan alokasi sumberdaya, dapat mengendalikan persaingan antar pelabuhan perikanan yang terdekat. Setiap pelabuhan perikanan akan memainkan peran sesuai dengan kondisi yang dimilikinya.

Klasterisasi minapolitan menurut pelabuhan perikanan dapat dilakukan dengan 2 strategi. Pertama, setiap pelabuhan perikanan yang masuk katagori mandiri dan maju dapat sebagai lead dari cluster tersebut, sementara pelabuhan perikanan lain menjadi mitra/ pendukungnya.

Tabel 3. Faktor Kunci Keberhasilan dari Pelabuhan Perikanan yang Masuk dalam Katagori Maju Program Minapolitan.

Table 3. The Successful Key Factors of Minapolitan Program on Developed Fishing Ports in.

\begin{tabular}{|c|c|c|c|}
\hline \multicolumn{4}{|c|}{ Faktor Internal/Factor Internal } \\
\hline No & Kekuatan (S)/Strengths & No. & Kelemahan (W)/Weaknesses \\
\hline S1 & $\begin{array}{l}\text { Pelabuhan perikanan memiliki } \\
\text { infrastruktur yang memadai/Well } \\
\text { supported of fishing port infrastructure }\end{array}$ & W1 & $\begin{array}{l}\text { Manajemen/pengelolaan pelabuhan } \\
\text { perikanan yang tidak seragam/ Different } \\
\text { management system in type of fishing port }\end{array}$ \\
\hline S2 & $\begin{array}{l}\text { Pelabuhan perikanan memiliki sarana } \\
\text { pendukung yang memadai/Good } \\
\text { condition of supported facilities in } \\
\text { fishing port }\end{array}$ & W2 & $\begin{array}{l}\text { Pasokan ikan dan sistem distribusi ikan yang } \\
\text { tidak baik/Poor condition of fish supply and } \\
\text { distribution system }\end{array}$ \\
\hline \multicolumn{4}{|c|}{ Faktor Eksternal/ Factor Ekternal } \\
\hline No. & Peluang (0)/Opportunities & No. & Ancaman $(\mathrm{T}) /$ Threats \\
\hline 01 & $\begin{array}{l}\text { Terdapat dukungan dari Pemda untuk } \\
\text { mengembangkan pelabuhan perikanan/ } \\
\text { Well supported of local government for } \\
\text { developing fishing port }\end{array}$ & $\mathrm{T} 1$ & $\begin{array}{l}\text { Banyaknya kegiatan IUU Fishing di perairan } \\
\text { Indonesia/Many IUU fishing activities in } \\
\text { some catch areas }\end{array}$ \\
\hline $\mathrm{O} 2$ & $\begin{array}{l}\text { Tingginya harga ikan di pasar ekspor/ } \\
\text { High price of fish in international } \\
\text { market }\end{array}$ & $\mathrm{T} 2$ & $\begin{array}{l}\text { Adanya kebijakan Non Tarif pada pasar } \\
\text { ekspor/Non tariff barrier in international } \\
\text { market }\end{array}$ \\
\hline
\end{tabular}


Kedua, klasterisasi kawasan minapolitan dilakukan dengan mempertimbangkan Wilayah Pengelolaan Perikanan (WPP), dimana pada setiap WPP terdapat satu atau dua kawasan minapolitan yang didukung oleh beberapa pelabuhan perikanan.

Klasterisasi Minapolitan yang perlu dipertimbangkan adalah : 1) WPP 571 (Selat Malaka dan Laut Andaman) dengan kawasan inti di PPS Belawan dan mitranya di PPI Tanjung Beringin, PP Swasta Barelang, PPP Idi Rayeuk dan PPI Bengkalis; 2) WPP 572 (Samudera Hindia Sebelah Barat Sumatera dan Selat Sunda) memiliki dua kawasan inti yaitu: PPS Bungus dan PPN Sibolga 3) WPP 573 dengan kawasan inti di PPN Pelabuhan Ratu, PPP Tamperan dan PPP Muncar 4) WPP 711 (Selat Karimata, Laut Natuna dan Laut Cina Selatan) dengan dua kawasan inti yakni PPN Sungai Liat dan PPN Pemangkat 5) WPP 712 (Laut Jawa) mempunyai kawasan inti di PPN Pekalongan, PPN Brondong, dan PPS Nizam Zachman.

\section{PENUTUP}

Pada perikanan tangkap laut kebijakan yang terkait dengan program minapolitan perlu diarahkan pada pelabuhan perikanan yang masuk dalam katagori mandiri dan maju. Hal ini harus dilakukan untuk mengoptimalkan alokasi anggaran dan keterbatasan stok ikan. Strategi yang direkomendasikan diatas harus dilakukan pada zona inti yang masuk dalam katagori mandiri dan maju. Diluar zona inti terdapat zona pengembangan dan zona keterkaitan. Pada minapolitan tangkap laut zona keterkaitan ini sangat penting, karena zona ini merupakan pasar dari semua yang dihasilkan oleh zona inti.

Operasionalisasi pelaksanaan program minapolitan pada pelabuhan perikanan mandiri dan maju, secara manajerial relatif baik. Namun, pada dua katagori pelabuhan perikanan tersebut harus dilakukan beberapa terobosan untuk mengatasi keterbatasan kemampuan infrastruktur. Hasil penelitian ini menunjukkan infrastruktur terutama jalan raya dari dan ke pelabuhan perikanan, listrik, serta pabrik es merupakan infrastruktur yang harus segera dibenahi agar kegiatan pada pelabuhan perikanan dapat berkembang.

Pelaksanaan program minapolitan pada kawasan pelabuhan perikanan tertumpu pada upaya peningkatan produksi untuk memenuhi suplai ikan sebagai bahan baku, namun program ini harus dikembangkan untuk mendukung pengembangan industri perikanan dan pasar diluar kawasan pelabuhan perikanan, sehingga industri perikanan berkembang luas.

\section{DAFTAR PUSTAKA}

Anonim. 2010. Program Minapolitan. Kementerian Kelautan dan Perikanan. Jakarta.

Jhinghan, M.L. 1999. Pengertian dan Ciri Ekonomi Modern. Ekonomi Perencanaan dan Pembangunan. Raja Grafindo Peresada. Jakarta.

Saaty, T.L. 1993. Decision Making in Economic, Social and Technology Environments With the AHP. Univ. of Pitsbutg.

Sianipar, I.P.G dan H.M. Entang. 2008. TeknikTeknik Analisis Manajemen. Modul Diklat Kepemimpinan III. Lembaga Administrasi Negara. Jakarta.

Zulham, A., Y. Dewitasari, B. Wardono, M. Yulisti, H.M. Huda. 2010. Membangun Model Minapolitan Perikanan Bitung. Balai Besar Riset Sosial Ekonomi Kelautan dan Perikanan. Badan Penelitian dan Pengembangan Kelautan dan Perikanan. Jakarta.

Zulham, A., Y. Dewitasari dan E.S. Luhur. 2010. Perspektif Model Minapolitan Perikanan Tangkap Laut. Balai Besar Penelitian Sosial Ekonomi Kelautan dan Perikanan. Badan Penelitian dan Pengembangan Kelautan dan Perikanan. Jakarta.

Zulham, A., S. Saptanto, T. Apriliani, A.H. Huda dan R.E. Rachmawati. 2011. Pemetaan Model Pengembangan Kawasan Minapolitan Tangkap Laut. Balai Besar Riset Sosial Ekonomi Kelautan dan Perikanan. Badan Penelitian dan Pengembangan Kelautan dan Perikanan. Jakarta. 
Lampiran 1. Peta Indeks Kesiapan Pelaksanaan Program Minapolitan.

Appendix 1. The Readiness Index Mapping of Fishing Port of Minapolitan Programm.

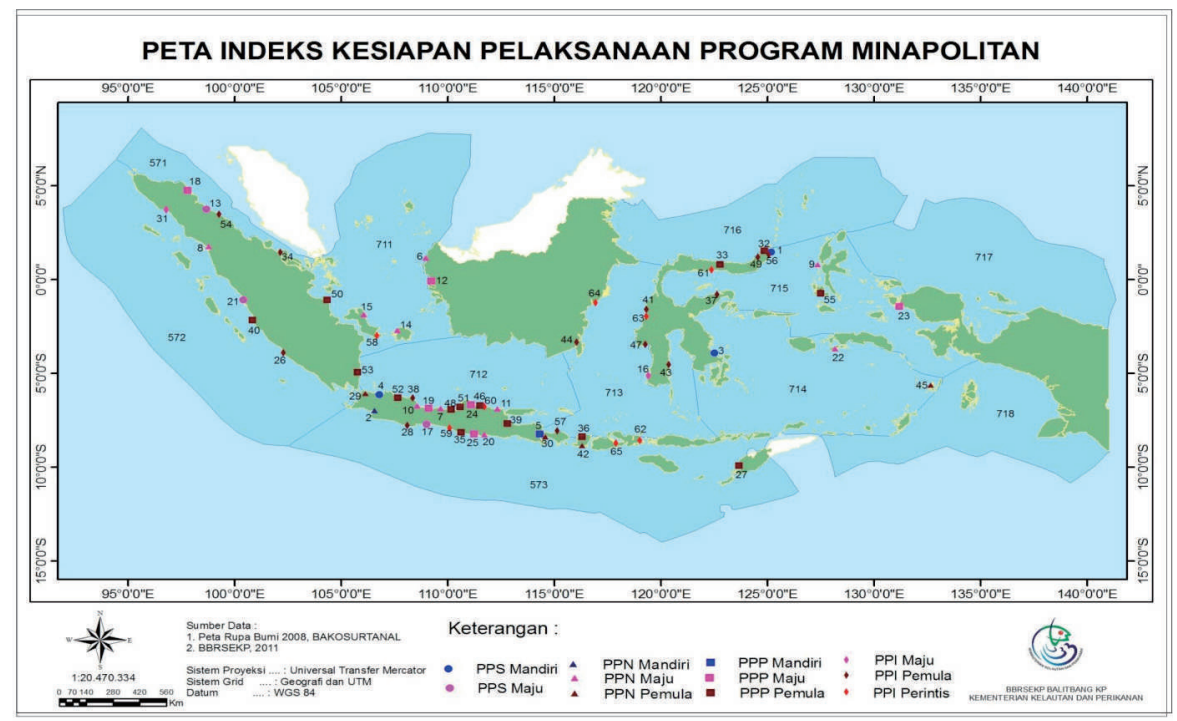

Keterangan: Nama pelabuhan perikanan

Remark : Fishing ports

\begin{tabular}{clclll}
\hline No & $\begin{array}{c}\text { Nama Pelabuhan/ } \\
\text { Name of fishing port }\end{array}$ & $\begin{array}{c}\text { No/ } \\
\text { No }\end{array}$ & $\begin{array}{c}\text { Nama Pelabuhan/ } \\
\text { Name of Fishing Port }\end{array}$ & $\begin{array}{c}\text { No/ } \\
\text { No }\end{array}$ & $\begin{array}{c}\text { Nama Pelabuhan } \\
\text { Name of Fishing ports }\end{array}$ \\
\hline 1 & PPS Bitung & 24 & PPP Bajomulyo & 46 & PPP Tasik Agung \\
2 & PPN Palabuhanratu & 25 & PPP Tamperan & 47 & PPI Lantora \\
3 & PPS Kendari & 26 & PPI Bengkulu & 48 & PPP Pantai Tawang \\
4 & PPS Nizam Zachman & 27 & PPP Kupang & 49 & PPI Amurang \\
5 & PPP Muncar & 28 & PPI Pamayangsari & 50 & PPP Kuala Tungkal \\
6 & PPN Pemangkat & 29 & PPN Karangantu & 51 & PPP Morodemak \\
7 & PPN Pekalongan & 30 & PPN Pengambengan & 52 & PPP Muara Ciasem \\
8 & PPN Sibolga & 31 & PPI Ujung Serangga & 53 & PPP Labuhan Maringgai \\
9 & PPN Ternate & 32 & PPP Tumumpa & 54 & PPI Beringin \\
10 & PPN Kejawanan & 33 & PPP Kwandang & 55 & PPN Bacan \\
11 & PPN Brondong & 34 & PPI Bengkalis & 56 & PPI Kema \\
12 & PPP Sungai Rengas & 35 & PPP Sadeng & 57 & PPI Sangit Singaraja \\
13 & PPS Belawan & 36 & PPP Labuhan Lombok & 58 & PPI Sadai \\
14 & PPN Tanjung Pandan & 37 & PPI Pagimana & 59 & PPI Tanjung Adikarto \\
15 & PPN Sungailiat & 38 & PPI Karangsong & 60 & PPI Bulu-Tuban \\
16 & PPI Paotere & 39 & PPP Wayangan & 61 & PPI Tilamuta \\
17 & PPS Cilacap & 40 & PPP Carocok Tarusan & 62 & PPI Sape \\
18 & PPP IDI & 41 & PPI Banggae & 63 & PPI Kasiwa \\
19 & PPP Tegal Sari & 42 & PPN Teluk awang & 64 & PPI Manggar Baru \\
20 & PPN Prigi & 43 & PPI Lonrae & 65 & PPI Teluk Santong \\
21 & PPS Bungus & 44 & PPI Batu Licin & & \\
22 & PPN Ambon & 45 & PPN Tual & & \\
23 & PPP Sorong & & & & \\
\hline & & & & &
\end{tabular}




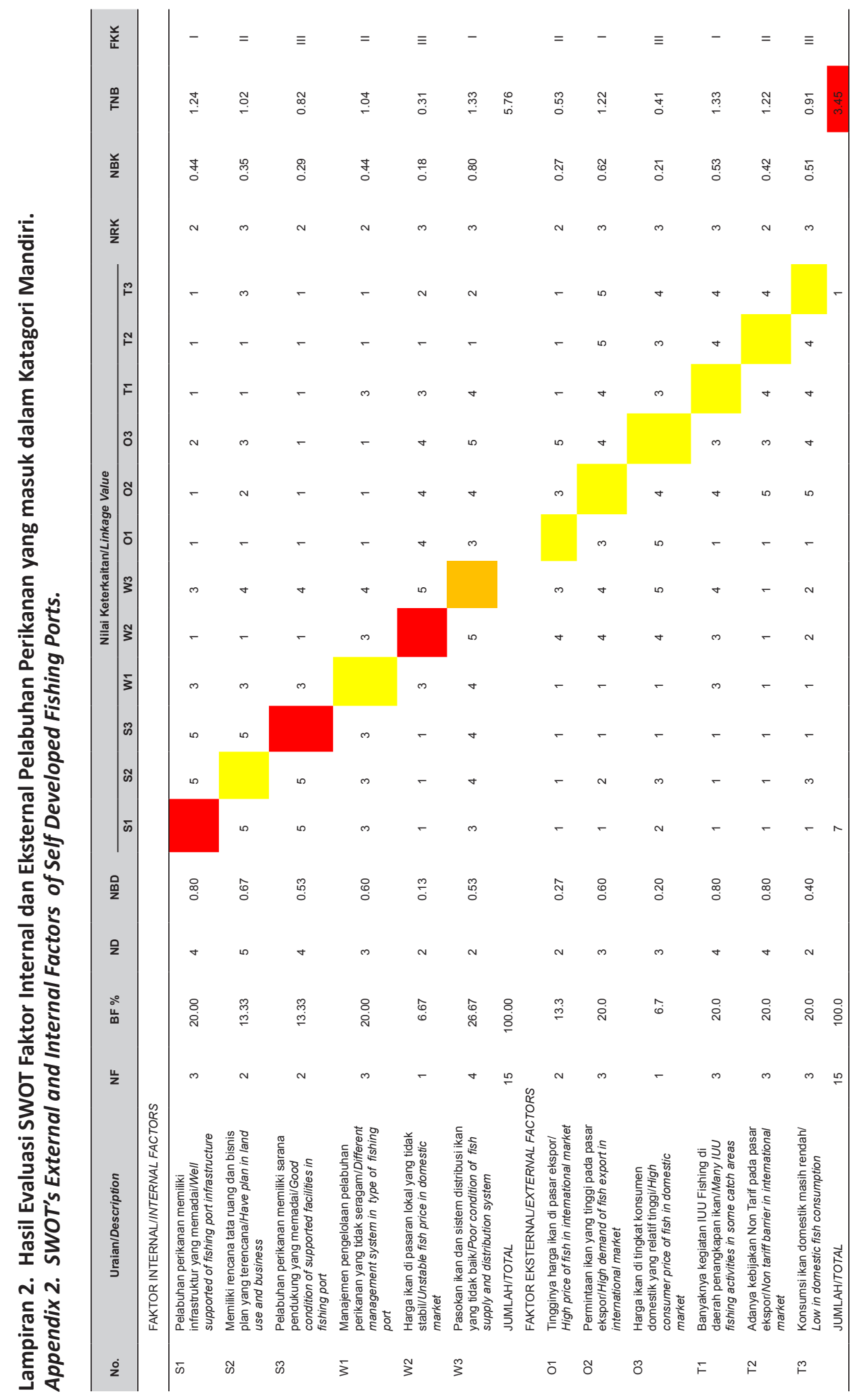




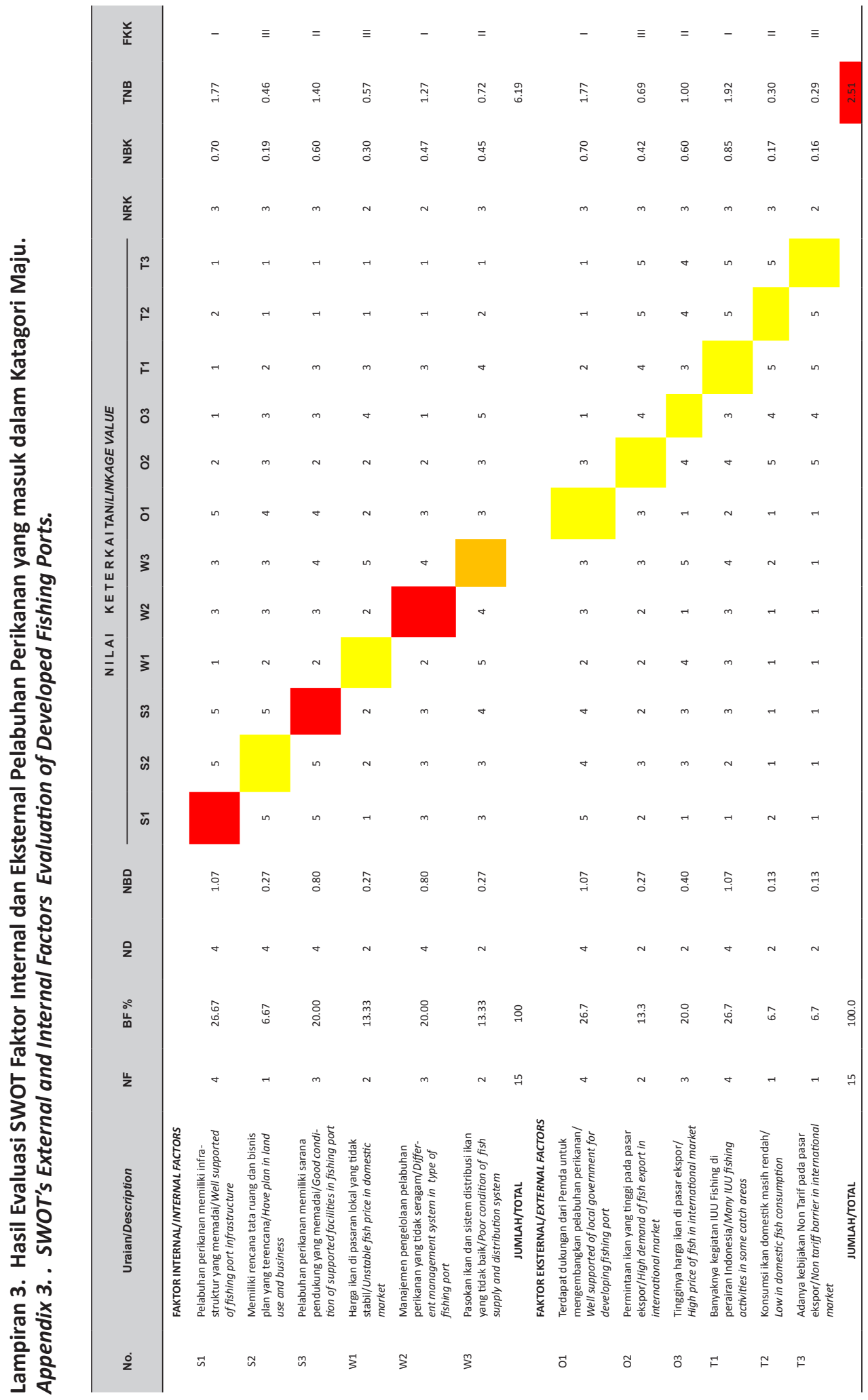

